Check for updates

Cite this: Chem. Sci., 2019, 10, 10601

A All publication charges for this article have been paid for by the Royal Society of Chemistry

Received 19th August 2019

Accepted 30th September 2019

DOI: $10.1039 /$ c9sc04122b

rsc.li/chemical-science

\section{Cu-catalyzed C-C bond formation of vinylidene cyclopropanes with carbon nucleophiles $\uparrow$}

\author{
Jichao Chen, Shang Gao and Ming Chen (1)*
}

The development of $\mathrm{Cu}$-catalyzed addition of carbon nucleophiles to vinylidene cyclopropanes was reported. The reactions with 1,1-bisborylmethane provided homopropargylic boronate products by forming a $\mathrm{C}-\mathrm{C}$ bond at the terminal carbon atom of the allene moiety of vinylidene cyclopropanes. Alkynyl boronates are also suitable nucleophile precursors in reactions with vinylidene cyclopropanes, and skipped diynes were obtained in high yields. In addition, the $\mathrm{Cu}$-enolate generated from the initial addition of nucleophilic copper species to vinylidene cyclopropanes can be intercepted by an external electrophile. As such, vinylidene cyclopropane serves as a linchpin to connect a nucleophile and an electrophile by forming two carbon-carbon bonds sequentially.

\section{Introduction}

Vinylidene cyclopropanes are a class of molecules that have an allene moiety connected to a cyclopropane. ${ }^{1}$ Although highly strained (strain energy estimated to be about $50 \mathrm{kcal} \mathrm{mol}^{-1}$ ), ${ }^{1 b}$ vinylidene cyclopropanes are stable at ambient temperature, and can be readily prepared from commercially available materials. ${ }^{1,2}$ However, under appropriate reaction conditions (Lewis acidic conditions, for example), vinylidene cyclopropanes have been shown to participate in reactions to generate carbocycles and heterocycles that are useful building blocks in organic synthesis. ${ }^{3}$ Several transition metal-catalyzed transformations of vinylidene cyclopropanes have also been investigated. ${ }^{2,3 a-c}$

Recently, Cu-based nucleophiles, including boron, silicon and hydrogen, have been shown to react with allenes to form allylcopper species. ${ }^{4-7}$ However, few methods are currently available allowing for catalytic reactions of Cu-based carbon nucleophiles with allenes. ${ }^{8}$ We developed and report herein our studies on $\mathrm{Cu}$-catalyzed reactions of vinylidene cyclopropanes with carbon nucleophiles generated from 1,1-bisborylmethane and alkynyl boronates to deliver synthetically useful homopropargylic boronate and skipped diyne products.

When considering the reaction pathways of $\mathrm{Cu}$-based carbon nucleophiles with vinylidene cyclopropanes A, two potential scenarios may arise in this process as illustrated in Scheme 1. Based on a plethora of prior studies on copper catalyzed reactions with allenes, ${ }^{4-7}$ it is anticipated that the addition of nucleophilic copper species [Cu]-R to vinylidene cyclopropane

Department of Chemistry and Biochemistry, Auburn University, Auburn, AL 36849, USA.E-mail:mzc0102@auburn.edu

† Electronic supplementary information (ESI) available. See DOI: 10.1039/c9sc04122b
A should occur in a pathway where the $\mathrm{R}$ group adds to the central carbon atom of the allene moiety to generate allylcopper intermediate $\mathbf{B}$ (pathway 1, shown in blue in Scheme 1). Interception of intermediate $\mathbf{B}$ with a source of proton should provide vinyl cyclopropane product $\mathbf{C}$ (or an alkylidene cyclopropane product). As such, the cyclopropane ring of $\mathbf{A}$ remains intact. Similar reaction pathways have also been observed in Ptcatalyzed hydroboration of vinylidene cyclopropanes. ${ }^{2}$ On the other hand, it is also conceivable that the migratory insertion step may occur with $\mathrm{R}$ group adding to the terminal carbon atom of the allene moiety to form vinylcopper intermediate $\mathbf{D}$ (pathway 2, shown in red in Scheme 1). ${ }^{9}$ Vinylcopper $\mathbf{D}$ could undergo a subsequent $\beta$-carbo elimination to open the cyclopropane ring to form homopropargylic copper intermediate $\mathbf{E}$, which can react with a proton source to give alkyne product $\mathbf{F}$. At the outset of our studies, it is not clear which pathway will be favoured in reactions with vinylidene cyclopropane A. However, in the case where $\mathrm{E}^{1}$ and $\mathrm{E}^{2}$ substituents in $\mathbf{A}$ are electronwithdrawing groups (ester group for instance), we anticipate that pathway 2 (shown in red in Scheme 1) should be more favourable because $\beta$-carbo elimination of intermediate (D) will generate a stabilized $\mathrm{Cu}$-enolate (e.g., E). Moreover, releasing the ring strain of cyclopropane in compounds $\mathbf{A}$ and $\mathbf{D}$ may also serve as a thermodynamic driving force for this reaction pathway.

\section{Results and discussion}

To test our hypothesis, vinylidene cyclopropane 1a bearing two methyl ester groups was synthesized, and reactions with 1,1bisborylmethane $2^{10}$ were conducted. It has been shown that 1,1-bisborylmethane 2 readily undergoes transmetalation with a copper catalyst under basic conditions to give a nucleophilic $\mathrm{Cu}-\mathrm{CH}_{2} \mathrm{Bp}$ in species that can react with carbonyl, imine or 


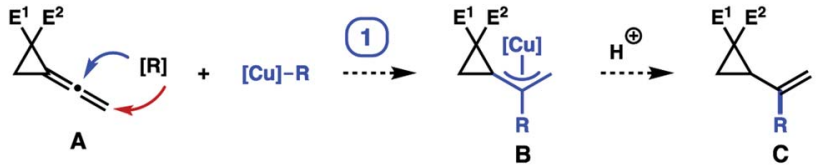

(2) $[\mathrm{Cu}]-\mathrm{R}$

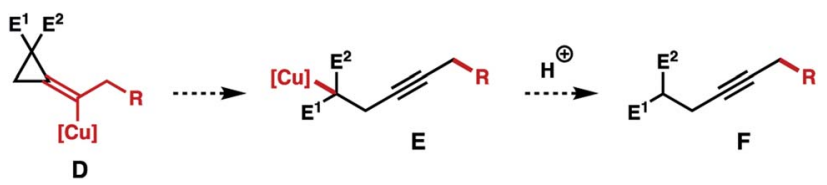

Scheme 1 Potential competing pathways for $\mathrm{Cu}$-catalyzed reactions with vinylidene cyclopropane.

allylic electrophiles. ${ }^{11,12}$ However, the nature of base plays a significant role in the transmetalation process. To identify an appropriate base for this transformation, reactions conducted with several tert-butoxide bases were examined first. As shown in Table 1, the experiments were performed with $10 \mathrm{~mol} \% \mathrm{CuCl}$ as the catalyst and 1.1 equiv. base in THF at ambient temperature. The reaction with $\mathrm{LiO}^{t} \mathrm{Bu}$ as the base gave homopropargylic boronate $\mathbf{3 a}$ in $37 \%$ yield (entry 1 , Table 1 ). When $\mathrm{NaO}^{t} \mathrm{Bu}$ was employed as the base, the yield of boronate product improved significantly, and 3a was isolated in $80 \%$ yield (entry 2, Table 1). The reaction performed with $\mathrm{KO}^{t} \mathrm{Bu}$ as the base, however, gave product $3 \mathrm{a}$ in only $10 \%$ yield (entry 3 , Table 1 ). Reactions with several methoxide bases were examined next. The yield of 3a $(48 \%)$ in the reaction with LiOMe as the base (entry 4, Table 1) is similar to the one conducted with $\mathrm{LiO}^{t} \mathrm{Bu}$. The best results were achieved when NaOMe was utilized as the base, and homopropargylic boronate 3a was isolated in $87 \%$ yield (entry 5, Table 1). In contrast to the case of $\mathrm{KO}^{t} \mathrm{Bu}$,

Table 1 Development of conditions for the reaction of 1,1-bisborylmethane 2 with vinylidene cyclopropane $1 a^{a}$

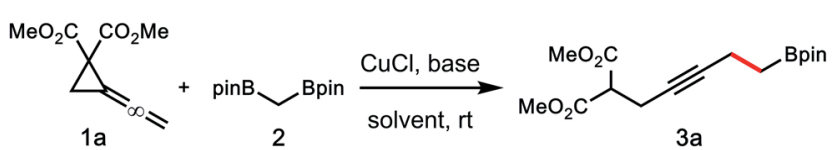

\begin{tabular}{llll}
\hline Entry & Base & Solvent & Yield $^{b}(\%)$ \\
\hline 1 & $\mathrm{LiO}^{t} \mathrm{Bu}$ & $\mathrm{THF}$ & 37 \\
2 & $\mathrm{NaO}^{t} \mathrm{Bu}$ & $\mathrm{THF}$ & 80 \\
3 & $\mathrm{KO}^{t} \mathrm{Bu}$ & $\mathrm{THF}$ & 10 \\
4 & $\mathrm{LiOMe}$ & $\mathrm{THF}$ & 48 \\
5 & NaOMe & THF & 87 \\
6 & KOMe & THF & 63 \\
$7^{c}$ & NaOMe & THF & 65 \\
8 & NaOMe & Toluene & 62 \\
9 & No base & THF & NR \\
$10^{d}$ & NaOMe & THF & NR
\end{tabular}

${ }^{a}$ Vinylidene cyclopropane 1a $(0.1 \mathrm{mmol}, 1$ equiv.), $\mathrm{CuCl}$ (10 mol\%), pinBCH ${ }_{2}$ Bpin $2(0.11 \mathrm{mmol}, 1.1$ equiv.), base ( $0.11 \mathrm{mmol}, 1.1$ equiv.), THF $(0.5 \mathrm{~mL}) .{ }^{b}$ Yields of isolated products are listed. ${ }^{c} 10 \mathrm{~mol} \%$ of xantphos was added to the reaction. ${ }^{d}$ The reaction was conducted in the absence of $\mathrm{CuCl}$. boronate 3a was generated in a substantial yield ( $63 \%$ vs. 10\%) with KOMe as the base (entry 6, Table 1). The presence of a bidentate phosphine ligand appears to slightly affect the efficiency of the transformation, as the reaction with $10 \mathrm{~mol} \%$ of xantphos gave product 3a in $65 \%$ yield (entry 7 , Table 1). The reaction conducted in toluene without the ligand also gave a lower yield of $\mathbf{3 a}$ (entry 8, Table 1). In all cases, the reactions proceeded through the ring-opening pathway to give homopropargylic boronate $\mathbf{3 a}$ as the product (pathway 2 in Scheme 1). Formation of vinyl cyclopropane or alkylidene cyclopropane product (derived from pathway 1 in Scheme 1) was not detected. The presence of a base and the copper catalyst is required for this transformation. A detectable amount product 3a was not formed without the added base (entry 9, Table 1). Similarly, when the reaction of $\mathbf{1 a}, \mathbf{2}$ and NaOMe was conducted in the absence of the copper catalyst, formation of product $\mathbf{3 a}$ was again not detected, thereby eliminating a base-promoted deborylative alkylation pathway. ${ }^{13}$

Table 2 summarizes the scope of vinylidene cyclopropane $\mathbf{1}$ that participated in the reactions with 1,1-bisboryl methane 2 under the developed conditions. In general, these reactions

Table 2 Scope of vinylidene cyclopropane 1 for reactions with bis [(pinacolato)boryl]methane $2^{a, b}$

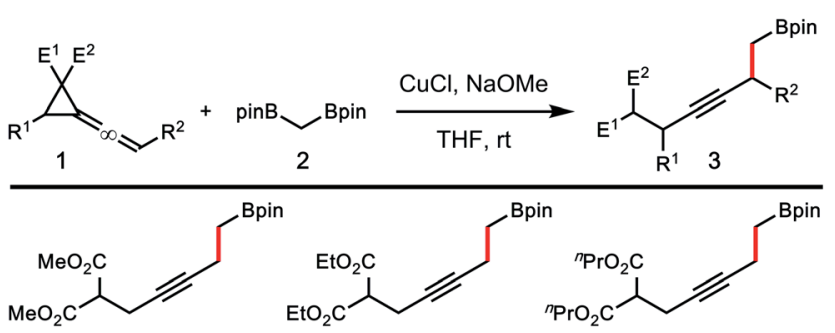

$3 a, 87 \%$

$3 b, 77 \%$

$3 c, 68 \%$
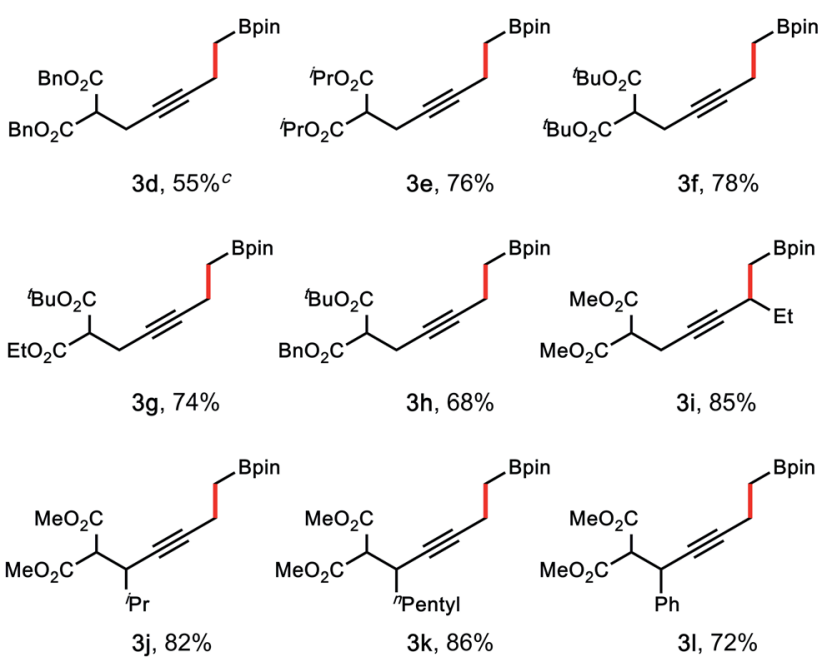

${ }^{a}$ Vinylidene cyclopropane 1 ( $0.1 \mathrm{mmol}, 1$ equiv.), $\mathrm{CuCl}$ (10 mol\%), pinBCH${ }_{2}$ Bpin 2 ( $0.11 \mathrm{mmol}, 1.1$ equiv.), NaOMe (0.11 mmol, 1.1 equiv.), THF $(0.5 \mathrm{~mL}) .{ }^{b}$ Yields of isolated products are listed. ${ }^{c} \mathrm{NaO}^{t} \mathrm{Bu}$ was used as the base. A tert-butyl ester byproduct derived from ester exchange was also isolated $(\sim 10 \%)$. 
worked well to give homopropargylic boronic ester products 3a$\mathbf{h}$ in $55-87 \%$ yields. In the case of $\mathbf{3 d}$, a by-product derived from ester exchange was also isolated $(\sim 10 \%)$. The developed conditions are also suitable for reactions of vinylidene cyclopropanes with different substitution patterns. For instance, the reaction of 1,1-bisborylmethane 2 with vinylidene cyclopropane bearing an ethyl group at the terminal olefin unit of the allene $\left(\mathrm{R}^{1}=\mathrm{H}, \mathrm{R}^{2}=\mathrm{Et}\right)$ gave product $3 \mathrm{i}$ in $85 \%$ yield. A variety of substitution groups on the cyclopropane ring are tolerated under the reaction conditions. Reactions of 2 with vinylidene cyclopropanes substituted with ${ }^{\mathrm{i}} \mathrm{Pr}-,{ }^{n}$ pentyl-, or Ph-group proceeded smoothly to give products $\mathbf{3} \mathbf{j}-\mathbf{1}$ in $72-86 \%$ yields. In all cases, formation of vinyl cyclopropane product (e.g., $\mathbf{C}$ in Scheme 1) was not observed.

Skipped diynes (e.g., 5, Scheme 2) are useful intermediates in organic synthesis as the alkyne units can undergo a variety of functional group transformations. In particular, they can serve as important precursors to numerous fatty acid natural products. ${ }^{14}$ Therefore, a novel approach to access skipped diynes would be valuable. Based on the results obtained from Tables 1 and 2, we envisioned that skipped diynes 5 could be prepared from the reaction of vinylidene cyclopropanes $\mathbf{1}$ with an alkyne nucleophile (Scheme 2). Initial experiments using lithiated alkynes under the Cu-catalyzed reaction conditions failed to produce an appreciable amount of skipped diynes 5. However, we discovered that the targeted skipped diyne 5a was generated from the reaction of vinylidene cyclopropane 1a with alkynyl boronate $\mathbf{4 a}$ as the nucleophile precursor. After further optimization of the reaction conditions, $\mathrm{NaO}^{t} \mathrm{Bu}$ was identified as the choice of base for $\mathrm{Cu}$-catalyzed reactions of $\mathbf{1}$ with alkynyl boronate $\mathbf{4}$, and the reaction of $\mathbf{1 a}$ with boronate $\mathbf{4 a}$ produced diyne $5 \mathbf{a}$ in $76 \%$ yield (Scheme 2 ).

The developed conditions were adopted to explore the scope of vinylidene cyclopropane 1 and alkynyl boronic ester 4. As summarized in Table 3, a variety of alkynyl boronates, including alkyl, aryl or ${ }^{t} \mathrm{BuMe}_{2}$ Si-group substituted boronates, participated in the reactions with vinylidene cyclopropanes 1 to give skipped diynes $\mathbf{5 a - 1}$ in 53-87\% yield. It appears that the aryl substituted alkynyl boronic esters are less reactive than alkyl substituted ones as shown in cases of $\mathbf{5 g}$ and $\mathbf{5 h}$.

Although it is known that nucleophilic copper species can react with alkyl halides to form alkylation products; the results from $5 \mathbf{i}-\mathbf{j}$ demonstrated that the reaction conditions tolerate alkyl chlorides. Reactions with vinylidene cyclopropanes substituted either on the cyclopropane group or at the terminal
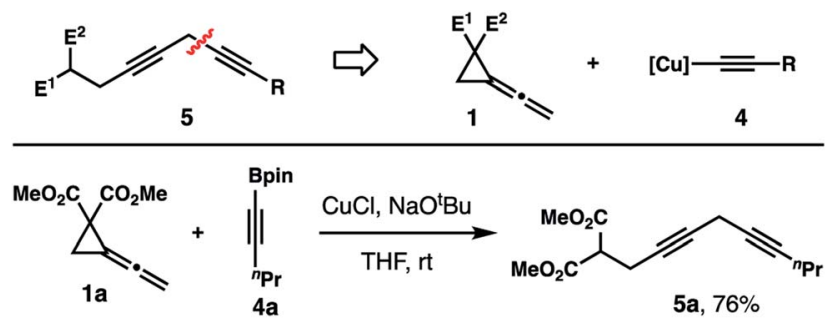

Scheme 2 Proposed synthesis of skipped diynes from Cu-catalyzed alkyne addition to vinylidene cyclopropanes.
Table 3 Scope of vinylidene cyclopropane 1 and alkynyl boronate 4 for the synthesis of skipped diynes $5^{a, b}$

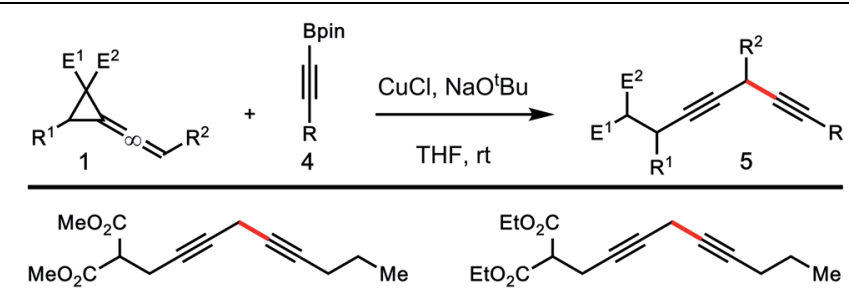

$5 a, 76 \%$

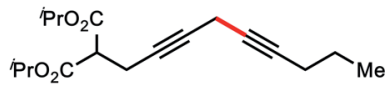

$5 c, 81 \%$<smiles>CCCC#CCC#CCC(C(=O)OCc1ccccc1)C(=O)OCc1ccccc1</smiles>

$5 e, 82 \%$<smiles>COCC(CC#CCC#Cc1ccccc1)C(OC)OC</smiles>

$5 g, 53 \%$<smiles>COCC(CC#CCC#CCCCCl)C(OC)OC</smiles><smiles>COCC#CCC#CCC(C(=O)O)C(=O)OC</smiles>

$5 \mathrm{k}, 78 \%$

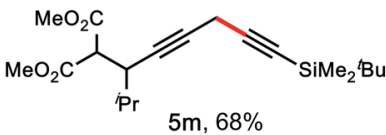<smiles>CCCCCCC(C#CCC(C#CCC(CC)C(C)=O)C(C)=O)OC</smiles>

$50,83 \%$

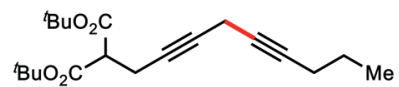

$5 d, 69 \%$
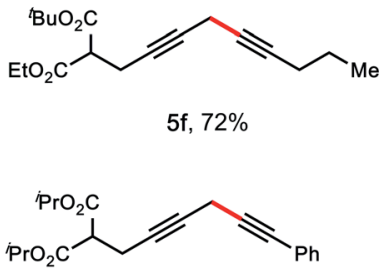

$5 \mathrm{~h}, 56 \%$
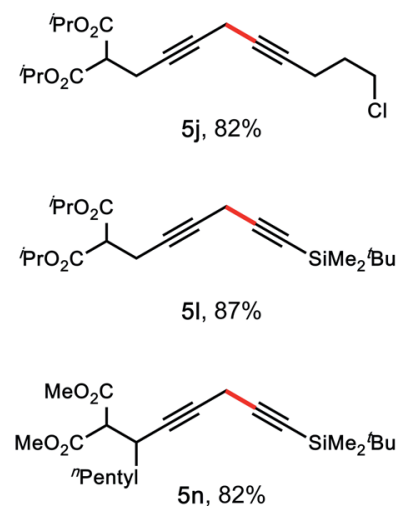

$5 n, 82 \%$
${ }^{a}$ Vinylidene cyclopropane 1 (0.1 mmol, 1 equiv.), CuCl (10 mol\%), alkynyl boronate 4 (0.11 mmol, 1.1 equiv.), $\mathrm{NaO}^{t} \mathrm{Bu}(0.11 \mathrm{mmol}, 1.1$ equiv.), THF (0.5 mL). ${ }^{b}$ Yields of isolated products are listed.

olefin unit of the allene moiety of $\mathbf{1}$ proceeded smoothly to give products 5m-o in $68-83 \%$ yields.

As shown in Scheme 3, the initial addition of nucleophilic $[\mathrm{Cu}]-\mathrm{R}$ species to vinylidene cyclopropane 1a should generate vinylcopper intermediate $\mathbf{D}$, which underwent a subsequent $\beta$ carbo elimination to open the cyclopropane ring to produce $\mathrm{Cu}$ [C]-enolate $\mathbf{E}$ or $\mathbf{C u}$-[O]-enolate $\mathbf{G}$ (or a mixture of two species). We surmised that, in the presence of an electrophile (other than proton), Cu-enolate $\mathbf{E}$ or $\mathbf{G}$ should react with the electrophile to 


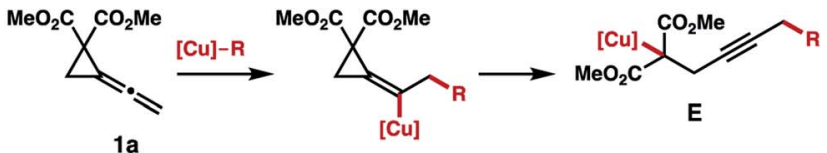

D
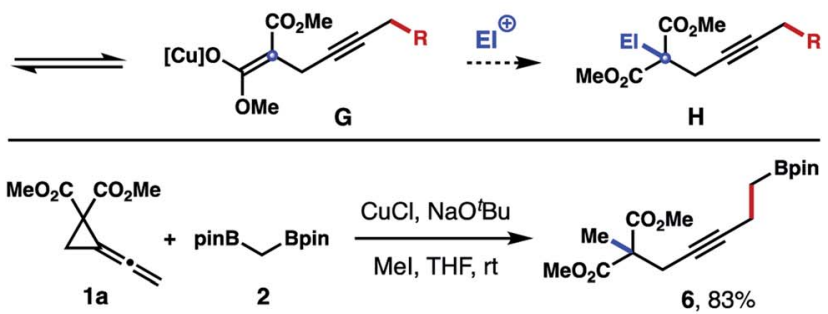

$6,83 \%$
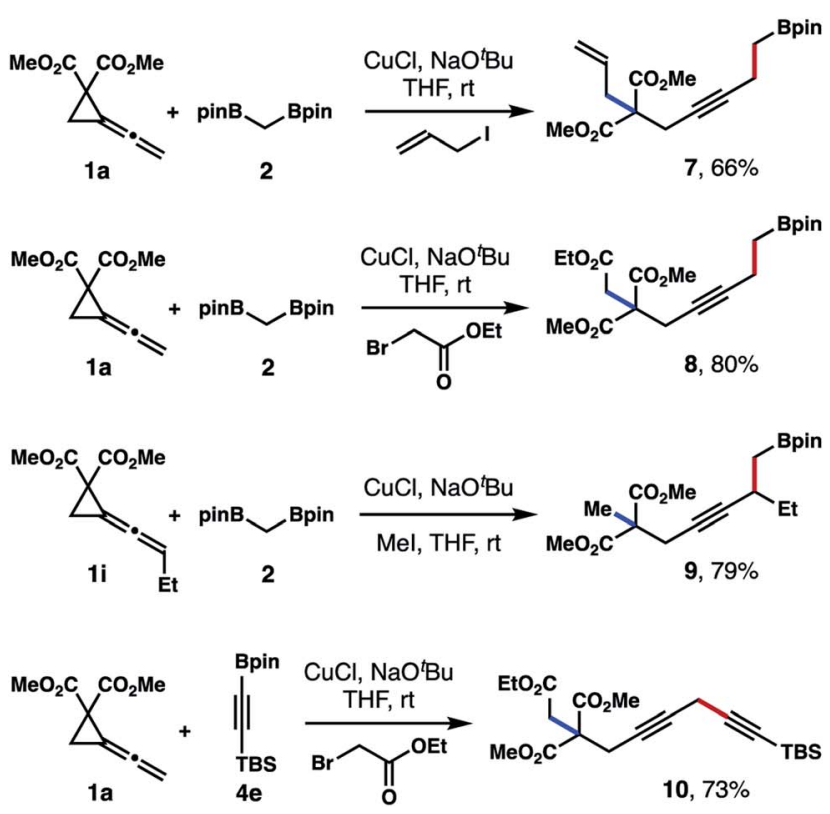

Scheme 3 Three-component reaction of vinylidene cyclopropanes, $\mathrm{Cu}$-nucleophiles and electrophiles. Reaction conditions: vinylidene cyclopropane 1 (0.1 mmol, 1 equiv.), CuCl (10 mol\%), 1,1-bisborylmethane 2 or alkynyl boronate $4 \mathrm{e}\left(0.11 \mathrm{mmol}, 1.1\right.$ equiv.), $\mathrm{NaO}^{t} \mathrm{Bu}$ (0.11 mmol, 1.1 equiv.), electrophile (2 equiv.), THF ( $0.5 \mathrm{~mL})$. Yields of isolated products are listed.

give product $\mathbf{H}$. However, to implement such a process, it is required that the reaction rate of vinylidene cyclopropane 1 with copper nucleophile $[\mathrm{Cu}]-\mathrm{R}$ is much faster than the reaction rate of external electrophiles with the copper nucleophile to minimize the formation of side products generated from $[\mathrm{Cu}]-\mathrm{R}$ and electrophiles (for example, R-El).

To validate our hypothesis, the reaction of vinylidene cyclopropane 1a with 1,1-bisboryl methane 2 was conducted in the presence of MeI. Gratifyingly, methylated boronate $\mathbf{6}$ was isolated in $83 \%$ yield from the reaction (Scheme 3). Product generated from deborylative methylation of 2 (e.g., Et-Bpin) was not detected. In addition to MeI, other electrophiles can also be used to intercept the $\mathrm{Cu}$-enolate. For instance, when allylic iodide was used, allylated product 7 was isolated in $66 \%$ yield. Trapping the copper enolate with ethyl bromoacetate gave product 8 in $80 \%$ yield. Vinylidene cyclopropane with an ethyl
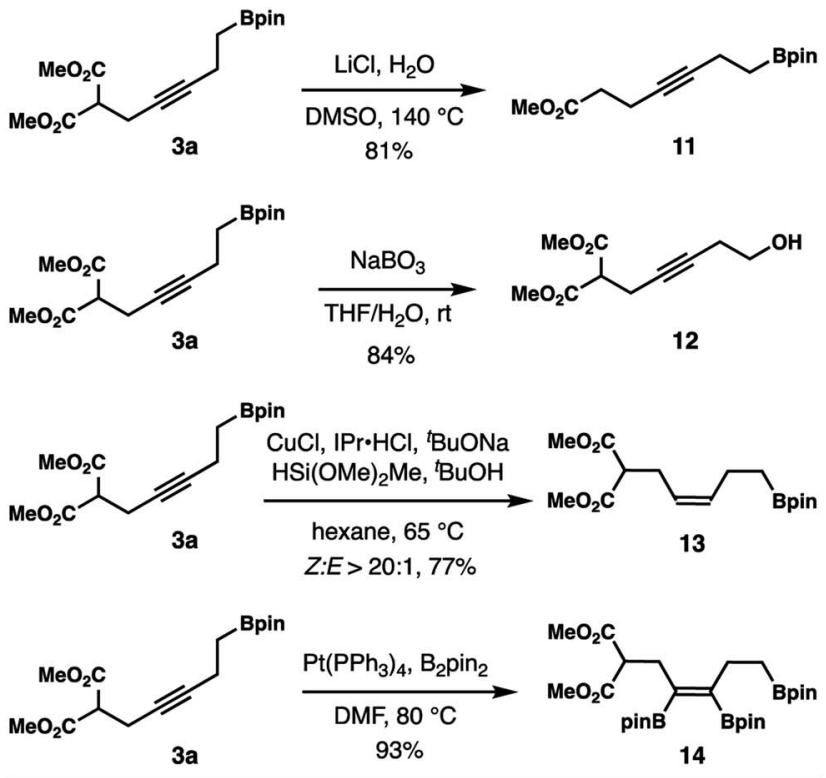

$5 \mathbf{a}$

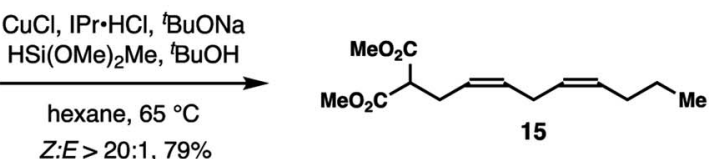

$Z: E>20: 1,79 \%$

5g
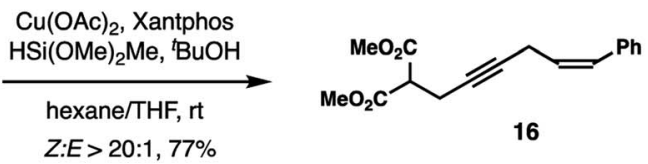

Scheme 4 Transformation of the reaction products.

group at the allene unit (1i) also participated in the threecomponent reaction to give product 9 in $79 \%$ yield. Intercepting the Cu-enolate generated from addition of alkynyl copper species to 1a with ethyl bromoacetate afforded product $\mathbf{1 0}$ in $73 \%$ yield. As such, vinylidene cyclopropane 1 serves as a linchpin to join a nucleophile ([Cu]-R) and an electrophile (El) by forming two carbon-carbon bonds sequentially (highlighted in red and blue in compounds 6-10, Scheme 3).

Derivatization of products obtained from these reactions is illustrated in Scheme 4. Decarboxylation of homopropargylic boronic ester 3a gave product $\mathbf{1 1}$ in $\mathbf{8 1} \%$ yield. Oxidation of $\mathbf{3 a}$ with $\mathrm{NaBO}_{3}$ produced alcohol 12 in $84 \%$ yield. Cu-catalyzed reduction of the alkyne group in 3a generated $Z$-alkene $\mathbf{1 3}$ in $77 \%$ yield with excellent selectivity. ${ }^{15}$ Boronate 3a participated in Pt-catalyzed alkyne diboration to furnish tetra-substituted alkene $\mathbf{1 4}$ in $93 \%$ yield. $^{16}$

Transformations of skipped diynes were also conducted. $Z$ Selective reduction of diyne $\mathbf{5 a}$ with excess silanes gave skipped $Z, Z$-diene 15 in $79 \%$ yield. ${ }^{15}$ Such a skipped $Z, Z$-diene is a common structure motif in many fatty acid natural products. Partial reduction of diyne $\mathbf{5 g}$ with silane reducing reagent turned out to be highly regioselective. ${ }^{15}$ Skipped enyne 16 was obtained in $77 \%$ yield with only the phenyl substituted alkyne group being reduced. Products derived from reduction of the other alkyne unit (alkyl substituted) or both alkynes were not observed. 


\section{Conclusions}

In summary, we developed Cu-catalyzed reactions of vinylidene cyclopropanes with carbon nucleophiles. These reactions proceeded through a ring-opening pathway to give products containing an alkyne group, which is distinct from the pathway typically involved in Cu-catalyzed addition of $\mathrm{B}, \mathrm{Si}$, or $\mathrm{H}$ nucleophiles to allenes. These reactions generated homopropargylic boronate and skipped diyne products in good yields from vinylidene cyclopropanes and carbon nucleophiles derived from 1,1-bisboryl methane and alkynyl boronates. In addition, the $\mathrm{Cu}$-enolate generated from the initial addition of nucleophilic copper species to vinylidene cyclopropanes can be intercepted by an external electrophile. As such, vinylidene cyclopropane serves as a linchpin to join a nucleophile and an electrophile by forming two carbon-carbon bonds sequentially. The reaction products underwent a variety of subsequent transformations to provide synthetically useful intermediates. Synthetic application of this method will be reported in due course.

\section{Conflicts of interest}

There are no conflicts to declare.

\section{Acknowledgements}

Financial support provided by Auburn University and Auburn Intramural Grants Program is gratefully acknowledged.

\section{Notes and references}

1 For selected reviews on vinylidene cyclopropanes, see: $(a)$ H. Maeda and K. Mizuno, J. Synth. Org. Chem., Jpn., 2004, 62, 1014; (b) M. Shi, L.-X. Shao, J.-M. Lu, Y. Wei, K. Mizuno and H. Maeda, Chem. Rev., 2010, 110, 5883; (c) S. Yang and M. Shi, Acc. Chem. Res., 2018, 51, 1667.

2 M. J. Campbell, P. D. Pohlhaus, G. Min, K. Ohmatsu and J. S. Johnson, J. Am. Chem. Soc., 2008, 130, 9180.

3 For selected recent references with vinylidene cyclopropanes, see: (a) S. Yang, K.-H. Rui, X.-Y. Tang, Q. Xu and M. Shi, J. Am. Chem. Soc., 2017, 139, 5957; (b) C. Ji, Q. Xu and M. Shi, Adv. Synth. Catal., 2017, 359, 974; (c) W. Yuan, X. Dong, M. Shi, P. McDowell and G. Li, Org. Lett., 2012, 14, 5582; (d) L. Wu and M. Shi, Chem.-Eur. J., 2011, 17, 13160; (e) L. Wu and M. Shi, Eur. J. Org. Chem., 2011, 2011, 1099; (f) L. Wu and M. Shi, Chem.-Eur. J., 2010, 16, 1149; (g) L. Wu and M. Shi, J. Org. Chem., 2010, 75, 2296.

4 For selected recent reviews: (a) K. Semba, T. Fujihara, J. Terao and Y. Tsuji, Tetrahedron, 2015, 71, 2183; (b) A. P. Pulis, K. Yeung and D. J. Procter, Chem. Sci., 2017, 8, 5240.

5 For selected recent references on $\mathrm{Cu}$-catalyzed reactions of allene with boron nucleophiles, see: (a) K. Semba, T. Fujihara, J. Terao and Y. Tsuji, Angew. Chem., Int. Ed., 2013, 52, 12400; (b) K. Semba, M. Shinomiya, T. Fujihara, J. Terao and Y. Tsuji, Chem.-Eur. J., 2013, 19, 7125; (c) W. Yuan, X. Zhang, Y. Yu and S. Ma, Chem.-Eur. J., 2013,
19, 7193; (d) F. Meng, K. P. McGrath and A. H. Hoveyda, Nature, 2014, 513, 367; (e) K. Semba, N. Bessho, T. Fujihara, J. Terao and Y. Tsuji, Angew. Chem., Int. Ed., 2014, 53, 9007; (f) F. Meng, X. Li, S. Torker, Y. Shi, X. Shen and A. H. Hoveyda, Nature, 2016, 537, 387; $(g)$ W. Zhao and J. Montgomery, J. Am. Chem. Soc., 2016, 138, 9763; (h) J. Zhao and K. J. Szabó, Angew. Chem., Int. Ed., 2016, 55, 1502; ( $i$ ) K. Yeung, R. E. Ruscoe, J. Rae, A. P. Pulis and D. J. Procter, Angew. Chem., Int. Ed., 2016, 55, 11912; (j) Y. Huang, S. Torker, X. Li, J. del Pozo and A. H. Hoveyda, Angew. Chem., Int. Ed., 2019, 58, 2685.

6 For selected recent references on $\mathrm{Cu}$-catalyzed reactions of allene with silicon nucleophile, see: (a) Y. Tani, T. Fujihara, J. Terao and Y. Tsuji, J. Am. Chem. Soc., 2014, 136, 17706; (b) J. Rae, Y. C. Hu and D. J. Procter, Chem.Eur. J., 2014, 20, 13143; (c) Z.-T. He, X.-Q. Tang, L.-B. Xie, M. Cheng, P. Tian and G.-Q. Lin, Angew. Chem., Int. Ed., 2015, 54, 14815; (d) T. Fujihara, A. Sawada, T. Yamaguchi, Y. Tani, J. Terao and Y. Tsuji, Angew. Chem., Int. Ed., 2017, 56, 1539.

7 For selected recent references on $\mathrm{Cu}$-catalyzed reactions of allene with hydrogen nucleophiles, see: (a) D. Zhao, K. Oisaki, M. Kanai and M. Shibasaki, J. Am. Chem. Soc., 2006, 128, 14440; (b) Y. Tani, K. Kuga, T. Fujihara, J. Terao and Y. Tsuji, Chem. Commun., 2015, 51, 13020; (c) R. Y. Liu, Y. Yang and S. L. Buchwald, Angew. Chem., Int. Ed., 2016, 55, 14077; (d) M. Lee, M. Nguyen, C. Brandt, W. Kaminsky and G. Lalic, Angew. Chem., Int. Ed., 2017, 56, 15703; (e) E. Y. Tsai, R. R. Liu, Y. Yang and S. L. Buchwald, J. Am. Chem. Soc., 2018, 140, 2007; (f) R. R. Liu, Y. Zhou, Y. Yang and S. L. Buchwald, J. Am. Chem. Soc., 2019, 141, 2251; $(g)$ G. Xu, B. Fu, H. Zhao, Y. Li, G. Zhang, Y. Wang, T. Xiong and Q. Zhang, Chem. Sci., 2019, 10, 1802.

8 T. Itoh, Y. Shimizu and M. Kanai, Org. Lett., 2014, 16, 2736.

9 For an example of reaction with allene to form a vinyl copper intermediate due to steric factors, see: W. Yuan, L. Song and S. Ma, Angew. Chem., Int. Ed., 2016, 55, 3140.

10 For selected reviews: (a) N. Miralles, R. J. Maza and E. Fernandez, Adv. Synth. Catal., 2018, 360, 1306; (b) R. Nallagonda, K. Padala and A. Masarwa, Org. Biomol. Chem., 2018, 16, 1050; (c) C. Wu and J. Wang, Tetrahedron Lett., 2018, 59, 2128.

11 For selected recent references on Cu-catalyzed reactions with 1,1-bisboryl alkanes, see: (a) M. V. Joannou, B. S. Moyer and S. J. Meek, J. Am. Chem. Soc., 2015, 137, 6176; (b) M. V. Joannou, B. S. Moyer, M. J. Goldfogel and S. J. Meek, Angew. Chem., Int. Ed., 2015, 54, 14141; (c) J. Kim, S. Park, J. Park and S. H. Cho, Angew. Chem., Int. Ed., 2016, 55, 1498; (d) Y. Shi and A. H. Hoveyda, Angew. Chem., Int. Ed., 2016, 55, 3455; (e) S. A. Murray, J. C. Green, S. B. Tailor and S. J. Meek, Angew. Chem., Int. Ed., 2016, 55, 9065; (f) Z.-Q. Zhang, B. Zhang, X. Lu, J.-H. Liu, X.-Y. Lu, B. Xiao and Y. Fu, Org. Lett., 2016, 18, 952; (g) J. Kim, K. Ko and S. H. Cho, Angew. Chem., Int. Ed., 2017, 56, 11584.

12 (a) T. Miura, J. Nakahashi and M. Murakami, Angew. Chem., Int. Ed., 2017, 56, 6989; (b) J. Park, S. Choi, Y. Lee and 
S. H. Cho, Org. Lett., 2017, 19, 4054; (c) S. Gao, J. Chen and M. Chen, Chem. Sci., 2019, 10, 3637.

13 (a) J. R. Coombs, L. Zhang and J. P. Morken, J. Am. Chem. Soc., 2014, 136, 16140; (b) K. Hong, X. Liu and J. P. Morken, J. Am. Chem. Soc., 2014, 136, 10581.

14 (a) S. Gueugnot, M. Alami, G. Linstrumelle, L. Mambu, Y. Petit and M. Larchevêque, Tetrahedron, 1996, 52, 6635; (b) Y. Suhara, S. Oka, A. Kittaka, H. Takayama, K. Waku and T. Sugiura, Bioorg. Med. Chem., 2007, 15, 854; (c)
M. A. Lapitskaya, L. L. Vasiljeva and K. K. A. Pivnitsky, Synthesis, 1993, 65; (d) V. R. Krishnamurthy, A. Dougherty, C. A. Haller and E. L. Chaikof, J. Org. Chem., 2011, 76, 5433; (e) L. Qi, M. M. Meijler, S.-H. Lee, C. Sun and K. D. Janda, Org. Lett., 2004, 6, 1673.

15 K. Semba, T. Fujihara, T.-H. Xu, J. Terao and Y. Tsuji, Adv. Synth. Catal., 2012, 354, 1542.

16 T. Ishiyama, N. Matsuda, N. Miyaura and A. Suzuki, J. Am. Chem. Soc., 1993, 115, 11018. 